\title{
Kinetic Parameters Survey for Manufacture of Pralidoxime
}

\author{
Daniel Antonio Shimizu Kitagawa ${ }^{1}$, Sabrina Teixeira Martinez ${ }^{2,3}$, Erick Braga Ferrao Galante ${ }^{2}$, \\ Tanos Celmar Costa Franca ${ }^{2,4}$ \\ ${ }^{1}$ Division of Chemical, Biological and Nuclear Defense, Technological Centre of Army, CTEx, Rio de Janeiro, Brazil \\ ${ }^{2}$ Chemical Engineering Department, Military Institute of Engineering, IME, Rio de Janeiro, Brazil \\ ${ }^{3}$ Organic Chemistry Department, Chemical Institute, Federal University of Rio de Janeiro, UFRJ, Rio de Janeiro, Brazil \\ ${ }^{4}$ Center for Basic and Applied Research, Faculty of Informatics and Management, University of Hradec Kralove, Hradec Kralove, Czech \\ Republic
}

\section{Email address:}

kitagawa@ctex.eb.br (D. A. S. Kitagawa), sabrinatmartinez@yahoo.com.br (S. T. Martinez), egalante@ime.eb.br (E. B. F. Galante), tanos@ime.eb.br (T. C. C. França)

\section{To cite this article:}

Daniel Antonio Shimizu Kitagawa, Sabrina Teixeira Martinez, Erick Braga Ferrão Galante, Tanos Celmar Costa Franca. Kinetic Parameters Survey for Manufacture of Pralidoxime. American Journal of Chemical Engineering. Vol. 3, No. 3, 2015, pp. 39-51. doi: 10.11648/j.ajche.20150303.12

\begin{abstract}
Chemical agents represent a serious threat to the modern world. Among them, they stand out nerve agents because of its high lethality and dangerousness. They are typically organophosphate compounds, which act by inhibiting acetylcholinesterase, a key enzyme in the transmission of nerve impulses process. There are several forms of treatment for organophosphate poisoning, and pralidoxime (2-PAM) is the drug most used as reactivator of acetylcholinesterase. In this work, we developed the first three steps for the synthesis of 2-PAM, with the objective of obtaining data to calculate the kinetic parameters of these steps. These parameters may be used for the manufacture of 2-PAM in semi-pilot scale. Through the studies conducted it has been found that the preparation of the oxime has very rapid kinetics.
\end{abstract}

Keywords: Chemicals warfare agents, Organophosphates compounds, Acetylcholinesterase, Oximes, Pralidoxime

\section{Introduction}

Chemical agents are a major threat to the modern world. One of its features is its danger, where small amounts can cause numerous poisonings. Moreover, they are easy to obtain and does not require many resources to manufacture. Thus, the use of chemical agents can be a dangerous alternative for organizations with limited resources, as underdeveloped countries and terrorist factions [1].

Among the chemicals the nerve agents stand out due to its high lethality. The neurotoxic substances are organophosphates (OP) which, in addition to its use as weapons, can also be used as pesticides. These compounds are inhibitors of acetylcholinesterase (AChE), an enzyme of great importance in controlling the transmission of nerve impulses.

A number of drugs are used in the treatment of poisoning by OP. Among these drugs are compounds containing the functional group oxime, whose function is to promote the reactivation of AChE. One of the most used oxime is pralidoxime or 2-PAM [(E) -2 - [(hydroxyimino) methyl] - pyridine] [1].

This work aimed to raise kinetic parameters of the reaction of synthesis of 2-PAM. The collection of kinetic parameters is a very important activity for the laboratorial chemical engineering, since it consists on the initial stage of semi pilot plant design for the manufacture of a chemical like 2-PAM.

\section{Chemical Agents and Neurotoxics}

There is a variety of chemical agents, each with different toxicological properties. According to the field manual C 3-40, chemical agent is any substance that through its chemical activity, produces, when used for military purposes, a toxic effect, smoke or fire. Chemical agents that produce a toxic effect may be classified as disabling, choking, vesicants, nerve and blood agents [2].

Incapacitating agents are those that cause temporary physiological and mental effects, preventing victims of combating. The most used are o-chlorobenzylmalonitrile (CS 
- cause eye irritation) and adamsite (DM - causes vomiting). Pulmonary toxicants, whose main agent is phosgene, act in the respiratory tract, causing lesions in capillaries and stroke in pulmonary alveoli, leading to suffocation. Vesicants are those that cause irritation and blistering of the skin and mucous membranes, and its most important agent is mustard gas. Blood agents, the most important being hydrogen cyanide, act interfering in tissue oxygenation, causing them quickly the state of necrosis and subsequent death. The neurotoxic, or nerve agents, are those that affect the nervous system, specifically the role of AChE [1].

The neurotoxics are highly toxic, both in vapor and in liquid



Figure 1. Nerve impulse transmission [5].
The first step is the release of a neurotransmitter, which is a substance stored inside the synaptic vesicles. These vesicles are located in the termination of the axon, which are the branches of neurons. Arriving at the termination of the axon, the nerve impulse causes the fusion of synaptic vesicles with the pre-synaptic membrane, releasing the neurotransmitter into the synaptic cleft.

The next step is the combination of the transmitter with the neurotransmitter receptors. The neurotransmitter diffuses across the synaptic cleft and binds to existing specialized receptors in the post-synaptic membrane.

Then it occurs the beginning of the post-junctional activity. Receptors change their conformation by binding to the transmitter and, then, the post-synaptic membrane becomes permeable to ions. Thus, increasing the concentration of sodium ions in the cytoplasm of the receiving neuron causes a potential difference, leading to a nerve impulse that will propagate in the neuron.

The last step is the dissipation of the transmitter. Because the pulses can be transmitted through the synaptic clefts, often at up to several hundred per second, there must be a mechanism to eliminate the transmitter for each pulse [4]. For this, there are enzymes in synaptic clefts which have the ability to hydrolyze the neurotransmitters, such as AChE (Figure 2), an enzyme belonging to the family of cholinesterase, whose function is to hydrolyze the neurotransmitter acetylcholine (ACh), as shown in Figure 3.

$\mathrm{AChE}$ and $\mathrm{ACh}$ are present in the $\mathrm{CNS}$ and peripheral nervous system (PNS). In the PNS AChE is connected to the form, because they are absorbed by the body through the skin or respiratory system. Symptoms include distress, loss of cause the collapse of the central nervous system (CNS) [3].

\subsection{Neurotransmission}

Neurotransmission or synaptic transmission is the transfer of nerve impulses from one neuron to another. Nerve impulses elicit responses in muscles, glands and postsynaptic neurons [4]. The neurotransmission can be divided into the four steps illustrated in Figure 1. coordination and seizures leading to death. These compounds

control of heart rate, dilation of blood vessels and smooth muscle contraction, whereas in the CNS it is involved in motor control, cognition and memory.

AChE plays an important role, because the accumulation of $\mathrm{ACh}$ in the synaptic cleft leads to overstimulation of the innervated structures, generating a cholinergic crisis, which has various effects such as seizures, cardiac arrhythmia and death [6].

In the active site of human AChE (Hss AChE) there are three amino acid residues (known as catalytic triad) directly involved in the ACh hydrolysis process, as shown in Figure 3. These amino acids are Ser203, Glu334 and His447. In the anionic active site there is a region, which serves to interact with the cationic portion of ACh by directing this substrate to the position necessary for hydrolysis [8].

The first step of the ACh hydrolysis process occurs through a nucleophilic attack by the hydroxyl group of Ser203 on the ester-carbonyl group of the substrate, promoting breakage of the ester bond [8]. During the enzymatic attack on the ester, it is formed an intermediate between the enzyme and the ester named acetylated Ser203 (acetyl-AChE complex). The acetyl-enzyme complex is easily hydrolyzed and this action, performed by water molecules, results in the formation of the fully regenerated acetate and the free enzyme.

The acetyl-AChE complex has a short life, making AChE one of the most efficient enzymes capable of hydrolyzing ACh on the order of $6 \times 10^{5}$ Ach molecules per molecule of enzyme per minute [8]. 




Figure 2. Hydrolysis of acetylcholine.



Figure 3. Simplified scheme of the HssAChE active site.

\subsection{Inhibition of $A C h E$}

Anticholinesterases are cholinesterase inhibitors. They are used as pesticides, anesthetics or in the treatment of myasthenia gravis, glaucoma and Alzheimer's disease [8].

The main anticholinesterase used as chemicals weapons are the OP compounds which are esters or thiols derived from phosphoric, phosphonic, phosphinic or phosphoramidic acid, having a central pentavalent phosphorus atom in their structure, with alkyl or aryl groups linked directly to this forming phosphinates (4) or through an oxygen atom or a sulfur atom forming phosphates (5), phosphorothionates (6), fosfonotioatos (7) and phosphonates (8) (Figure 4) [1].<smiles>[R]OP([R])([R])=O</smiles>

\section{phosphates}

(5)<smiles>[R]OP([R])([R])=S</smiles>

(6)<smiles>[R]OP([R])([R])=S</smiles>

phosphonothionates

(7)<smiles>[R]OP([R])([R])=O</smiles>

phosphonates

(8)

Figure 4. Types of OP compounds.

At the end of the 30s, a series of studies in Germany on the development of pesticides resulted in the synthesis of the neurotoxic agents of type G. In the 50s, in England, a class of more toxic and persistent nerve agents was developed and 
classified as type V [9]. The letter G refers to the country of origin "Germany" and the letter V denotes "Venomous" [10].
Examples of OP used as nerve agents and pesticides are shown in Figure 5. (a)<smiles>CCP(=O)(C#N)N(C)C</smiles>

GA (tabun) (9)<smiles>CC(C)OP(C)(=O)F</smiles>

GB (sarin) (10)<smiles>CC(C)(C)C(C(=O)P(C)(=O)F)C(C)(C)C</smiles>

GD (soman) (11)



GF (cyclosarin) (12)

(b)<smiles>CCOP(C)(=O)SCC[NH+](C)C(C)C</smiles>

VX (13)<smiles>[Y9]P(=O)(OCC(C)C)SCCN(CC)CC</smiles>

R-VX (14)

(c)<smiles>CCOP(=O)(OCC)Oc1ccc([N+](=O)[O-])cc1</smiles><smiles>CCOP(=S)(OCC)Oc1ccc([N+](=O)[O-])cc1</smiles>

Paraoxon (15)

Parathion (16)

Figure 5. (a) G neurotoxics, (b) Vneurotoxics, (c) pesticides.<smiles>CC(=O)O[Hg]n1cncc1C</smiles>

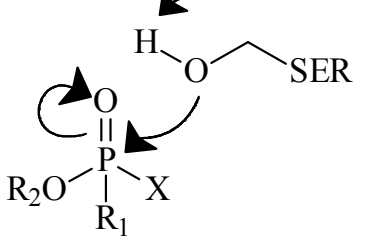



Organophosphorade<smiles>[R]SCOP([R1])(=O)[O-]</smiles>

Aged enzyme

<smiles></smiles><smiles>[R][SH]COP([R])([R20])=O</smiles>

Inactivated enzyme

Figure 6. AChE inibition (-X is the leaving group).

The best known neurotoxic agents are: tabun (GA), sarin (GB), soman (GD), cyclosarin (GF), and O-ethyl S- (2(diisopropylamino) ethyl)-metilfosfonotioato (VX). The codes GA, GB, GD, GF and VX were assigned by NATO to identify these chemicals [7].

The OP has high affinity for AChE that, once inhibited, will 
not be able to hydrolyze ACh anymore. The inhibition occurs within the active site on Ser203, via an interaction with the OP. Most OP bind covalently to Ser203. This connection occurs between the $\mathrm{P}$ atom of the $\mathrm{OP}$ and the serine $\mathrm{O}$ atom, with subsequent leaving of the $-\mathrm{X}$ group, as shown in mechanistic scheme in Figure 6 [11].

After inhibition of AChE by an OP, two situations may occur: aging or spontaneous reactivation of the enzyme. However, the reaction of reactivation occurs at a negligible rate, favoring the aging. The aging process occurs in an elimination reaction, or by spontaneous dealkylation of the $\mathrm{P}$ atom conjugated with $\mathrm{AChE}$, breaking the alkyl-oxygen bond and resulting in a very stable anion complex that characterizes the irreversible inhibition of AChE [3].

\subsection{Treatment}

The possibility of attacks involving neurotoxic agents is a strong reason for continuous research on the development of more effective antidotes against them. The chemotherapy used in the treatment of intoxication with OP includes the use of three types of drugs [1]: an anticholinergic, a depressor of the $\mathrm{CNS}$ and an oxime.

Anticholinergic compete with ACh by cholinergic receptors, antagonizing the effects of the accumulation of the neurotransmitter. Atropine (17), shown in Figure 7, is the most commonly anticholinergic, as it is effective in treating all OP, used as standard antidote since the late 1940s.

CNS depressants are used to alleviate seizures and muscle spasms commonly associated with acute poisoning by OP, with diazepam (18) (Figure 7) being the most used compound of this class.



Phosfhorilated enzyme<smiles>CN1C2CCC1CC(OC(=O)C(CO)c1ccccc1)C2</smiles>

Atropine (17)



Diazepam (18)

Figure 7. Structures of atropine and diazepam.<smiles>C[n+]1ccccc1/C=N/O</smiles>

Pralidoxime (2 - PAM) (19)<smiles>CC(C)(C)OCCC[n+]1ccc(CNO)cc1</smiles><smiles>ONCc1cc[n+](COC[n+]2ccc(CNO)cc2)cc1</smiles>

Figure 8. Strucutres of 2-PAM, trimedoxime and obidoxime.



Intermediate<smiles>[R]NO[PH+]([Z2])=O</smiles>

\section{Phosfhorilated oxime Reactivated enzyme}

Figure 9. Reactivation mechanism of AchE.

In 1951, it was shown that compounds containing nucleophilic groups such as oximes $(\mathrm{RCH}=\mathrm{NOH})$, hydroxylamines $\left(\mathrm{NH}_{2} \mathrm{OH}\right)$ and hydroxamic acids
(RCONH-OH) can be employed for the reactivation of AChE inhibited by OP [4]. The main reactivators of AChE are pralidoxime (19), trimedoxime (20) and obidoxime (21) 
(Figure 8). However, the reactivator works only if the inhibited enzyme is not aged since, if this happens, results in the formation of a stable phosphorylated enzyme, which cannot be reactivated. As the aging process of phosphorylated AChE depends on the time, the treatment depends on the effectiveness of the antidote administration immediately after exposure of the patient to the OP [11].

One mechanism proposed for the reactivation of AChE is shown in Figure 9. This mechanism suggests that the reactivation efficiency depends on the nucleophilicity of the reactivator, in this case the oximate. The oxime performs a nucleophilic attack on the $\mathrm{P}$ atom, forming the phosphorylated oxime that will be further released, regenerating the enzyme [12].

\subsection{Pralidoxime}

As mentioned before 2-PAM (pyridine-2-aldoxime) is an oxime used in the reactivation of AChE inhibited by OP [13]. In the United States, it is employed in the form of chloride and in the United Kingdom, it is used in the form of methane sulfonate [14].

A proposed synthesis of 2-PAM is described in Figure 10. First a condensation of pyridine-2-carboxaldehyde (22) with hydroxylamine to form the (E) -2 - [(hydroxyimino) methyl] pyridine (23) is performed [15].Then, this intermediate undergoes quaternization with methyl iodide [16]. Finally an anionic exchange is carried out to obtain 2-PAM [17].



(22)



(19)

Figure 10. Synthesis of 2-PAM.

\subsection{Industrial Production}

All industrial chemical process is designed to economically produce a desired product from a variety of raw materials through a succession of treatments [18]. These treatments may be physical, with the intention of improving the quality of the raw material or purify the product. However, there are chemical treatments that promote proper transformation of the raw in product through chemical reactions occurring in reactors.

Thus, chemical reactors are the most important equipment in any chemical industry [19]. In order to design reactors for the development of an industrial plant, reactors calculations are performed to predict the performance of a reactor in response to a set of specified requirements.

The studies of reactors calculations can be divided into two systems: microscopic and macroscopic [20]. The microscopic system, or molecular, is associated with the interaction between molecules, that is, is related to the kinetic, suffering great influence of the concentration and temperature of the reaction medium. On the other hand the macroscopic system considers all the phenomena involved in bringing the components of the reaction medium, since the solubilization of the crystals of solid components to the beginning of the interactions that trigger the chemical reaction. These phenomena influence the concentration gradients and the temperature distribution on the reaction medium. The study of the macroscopic systems involves concepts of thermodynamics, fluid mechanics, heat transfer and mass transfer.

All these concepts are fundamental to the calculation of reactors, where the information gathered in both systems allowed the early studies for the design of semi-pilot plants.

\subsubsection{Chemical Kinetics}

The chemical kinetics deals primarily with the reaction speed study, considering all the factors influencing it. Their study is of great importance for the chemical engineering because it allows information to determine some parameters of reactors, such as size, flow, thermal setting and others [20].

From the mass balances the design equations of the reactors can be determined. In a homogeneous batch reactor (constant temperature and concentration that does not vary in space), at constant volume, taking place the following irreversible reaction:

$$
A+B \rightarrow \text { Products }
$$

the design equation (1) is given by [21]:

$$
-d C_{A} / d t=-r_{A}
$$

where $C_{A}$ is the concentration of reagent " $A$ " and $-r_{A}$ is the consummation speed of "A".

The algebraic equation relating the reaction rate with the concentrations of the species is called speed law. It can be written as the product of a function which depends primarily on the temperature of the system with a function that depends on the concentrations of the reactants. For the above reaction it can be written as [21]:

$$
-r_{A}=k C_{A}^{\alpha} C_{B}^{\beta}
$$

where $\alpha$ and $\beta$ are the reaction orders and "k" is a constant reaction rate.

An experimental relationship between " $\mathrm{k}$ " and the reaction temperature was first proposed by Arrhenius [22, 23, 18]:

$$
k=k_{0} e^{\frac{E_{a}}{R T}}
$$

where $" \mathrm{k}_{0}$ " is the pre-exponential factor and " $\mathrm{E}_{\mathrm{a}}$ ", the activation energy. 
The rate law can be obtained from theoretical considerations or empirical procedures; however the kinetics parameters can only be determined experimentally [24]. The determination of these parameters is usually performed by measuring the concentration as a function of time and then applying a method for data analysis in order to determine the order of reaction and the rate constant [21].

One such method is the differential which gives the values of " $\alpha$ " and " $k$ " by numerical differentiation of the concentration data as a function of time without the need of assuming values for the parameters to be determined. This method is applied in irreversible reactions whose speed is essentially a function of the concentration of only one reactant.

First, the reaction is carried out with excess of B so that their concentration remains roughly unchanged. Thus, from the law of velocity and the design equation, one obtains [21]:

$$
-d C_{A} / d t=k_{A} C_{A}^{\alpha}
$$

Applying the natural logarithm to (4), we have:

$$
\ln \left(-d C_{A} / d t\right)=\ln k_{A}+\alpha \ln C_{A}
$$

For the derivative $-\mathrm{dC}_{\mathrm{A}} / \mathrm{dt}$ it is necessary to differentiate the data concentration versus time, either numerically or graphically. A numerical method to calculate derivatives is the finite difference [25].

Once computed derived, it is possible to find the order of the reaction and the rate constant from the graph $\ln \left(-\mathrm{dC}_{\mathrm{A}} / \mathrm{dt}\right)$ in function of $\ln \mathrm{C}_{\mathrm{A}}$, performing a linear fit to the data obtained by discrete approximation of least squares [26]. The slope of the graph is the value of " $\alpha$ " and the linear coefficient will be $\ln k_{A}$.

\subsubsection{Method of Finite Differences}

The method of finite differences is based on the Taylor series expansion:

$$
f(x)=f\left(x_{0}\right)+(\Delta x)|d f / d x|_{x_{0}}+(\Delta x)^{2} / 2 !\left|d^{2} f / d x^{2}\right|_{x_{0}}+\cdots
$$

Where $\Delta \mathrm{x}=\mathrm{x}-\mathrm{x}_{0}$. Expanding $\mathrm{f}\left(\mathrm{x}_{\mathrm{i}}+\Delta \mathrm{x}\right)$ in Taylor series around $\mathrm{x}_{\mathrm{i}}$, we have:

$$
f\left(x_{i}+\Delta x\right)=f\left(x_{i}\right)+(\Delta x)|d f / d x|_{x_{i}}+(\Delta x)^{2} / 2 !\left|d^{2} f / d x^{2}\right|_{x_{i}}+\cdots
$$

So:

$$
|d f / d x|_{x_{i}}=f\left(x_{i}+\Delta x\right)-f\left(x_{i}\right) /_{\Delta x+}+\left[-\Delta x / 2 !\left|d^{2} f / d x^{2}\right|_{x_{i}}-\cdots\right]
$$

Since the definition of derivative is:

$$
d f / d x=\lim _{\Delta x \rightarrow 0}\left(f\left(x_{i}+\Delta x\right)-f\left(x_{i}\right)\right) / \Delta x
$$

depending on the value of $\Delta x$, it's possible to consider the first term of (8) as an approximation of the derivative. Thus:

$$
|d f / d x|_{x_{i}}=\left(f\left(x_{i}+\Delta x\right)-f\left(x_{i}\right)\right) / \Delta x+L T E
$$

where LTE is the local truncation error.

Similarly, expanding $\mathrm{f}\left(\mathrm{x}_{\mathrm{i}}-\Delta \mathrm{x}\right)$ in Taylor series around $\mathrm{x}_{\mathrm{i}}$ :

$$
|d f / d x|_{x_{i}}=\left(f\left(x_{i}\right)-f\left(x_{i}-\Delta x\right)\right) / \Delta x+L T E
$$

Combining (10) and (11):

$|d f / d x|_{x_{i}}=\left(f\left(x_{i}+\Delta x\right)-f\left(x_{i}-\Delta x\right)\right) / 2 \Delta x+L T E$

Simplifying (12):

$$
|d f / d x|_{x_{i}}=\left(f_{i+1}-f_{i-1}\right) / 2 \Delta x+L T E
$$

Equation (13) uses $\mathrm{x}(\mathrm{i}+1)$ and $\mathrm{x}(\mathrm{i}-1)$ points to calculate the value of the derivative at the central point $x i$, thus it is called: "approximated by central differences". However, to calculate the derivative of the function $f$ at the point $\mathrm{x}_{\mathrm{i}}$, we can use only later points, so called progressive approach by differences, or only previous points, so called approach for late differences. These techniques are well used to determine the derivatives at the starting and ending points, respectively.

Using the three methods of finite differences, it is possible to calculate the derivative of the concentration of a component in a reaction medium as a function of time by the following equations:

$$
\begin{array}{r}
\left(-d C_{A} / d t\right)_{t_{0}}=\left(-3 C_{A 0}+4 C_{A 1}-C_{A 2}\right) / 2 \Delta t \\
\left(-d C_{A} / d t\right)_{t_{i}}=\left(C_{A(i+1)}-C_{A(i-1)}\right) / 2 \Delta t \\
\left(-d C_{A} / d t\right)_{t_{n}}==\left(C_{A(n-2)}-4 C_{A(n-1)}+3 C_{A n}\right) / 2 \Delta t
\end{array}
$$

\subsubsection{Least Squares Discrete Approach}

From a set of ordered pairs $\left(x_{i}, y_{i}\right)$, it is possible to determine a function $f(x)$ that enables the prediction of the intermediate values ordered pairs. This function is called the approach curve.

The method of discrete approximation of least squares consists in determining the best fitted curve involved when the error is the sum of the squares of the differences between the values of $f\left(x_{i}\right)$ obtained in the fitted curve and the values of $y_{i}$ data.

To make a $1^{\text {st }}$ degree polynomial fitted curve of a set of " $m$ " ordered pairs $\left(x_{i}, y_{i}\right)$ :

$$
f(x)=a_{1} x_{i}+a_{0}
$$

The "E" error is provided by:

$$
E\left(a_{1}, a_{0}\right)=\sum_{i=1}^{m}\left[y_{i}-\left(a_{1} x_{i}+a_{0}\right)\right]^{2}
$$


In order to minimize this error:

$$
\begin{aligned}
& 0=\frac{\partial}{\partial a_{1}}\left\{\sum\left[y_{i}-\left(a_{1} x_{i}+a_{0}\right)\right]^{2}\right\} \\
& 0=\frac{\partial}{\partial a_{0}}\left\{\sum\left[y_{i}-\left(a_{1} x_{i}+a_{0}\right)\right]^{2}\right\}
\end{aligned}
$$

Thus:

$$
\begin{aligned}
& a_{0}=\frac{\sum x_{i}^{2} \sum y_{i}-\sum x_{i} y_{i} \sum x_{i}}{m\left(\sum x_{i}{ }^{2}\right)-\left(\sum x_{i}\right)^{2}} \\
& a_{1}=\frac{m \sum x_{i} y_{i}-\sum x_{i} \sum y_{i}}{m\left(\sum x_{i}{ }^{2}\right)-\left(\sum x_{i}\right)^{2}}
\end{aligned}
$$

An example of application of the approach of least squares is observed in Figure 11, which represents the adjustment of the ordered pairs in Table 1.
Table 1. Example of the approach of least squares.

\begin{tabular}{llll}
\hline $\mathbf{x}_{\mathbf{i}}$ & $\mathbf{y}_{\mathbf{i}}$ & $\mathbf{x}_{\mathbf{i}}{ }^{2}$ & $\mathbf{x}_{\mathbf{i}} \mathbf{y}_{\mathbf{i}}$ \\
\hline 1 & 1,3 & 1 & 1,3 \\
2 & 3,5 & 4 & 7,0 \\
3 & 4,2 & 9 & 12,6 \\
4 & 5,0 & 16 & 20,0 \\
5 & 7,0 & 25 & 35,0 \\
6 & 8,8 & 36 & 52,8 \\
7 & 10,1 & 49 & 70,7 \\
8 & 12,5 & 64 & 100,0 \\
9 & 13,0 & 81 & 117,0 \\
10 & 15,6 & 100 & 156,0 \\
55 & 81,0 & 385 & 572,4 \\
\hline
\end{tabular}

Source: Numerical analysis [26]

$$
\begin{aligned}
& a_{0}=(385 \times 81-55 \times 572,4) /\left(10 \times 385-55^{2}\right)=-0,360 \\
& a_{1}=(10 \times 52,4-55 \times 81) /\left(10 \times 385-55^{2}\right)=1,538
\end{aligned}
$$



Figure 11. Value adjusts of data from Table 1.

\section{Materials and Methods}

Our study was executed in three stages. The first and the second steps consisted on the synthesis and characterization of compound 23, in order to confirm the chosen synthesis methodology. The third stage consisted in the survey of kinetic parameters by monitoring the evolution of the synthesis of compound 23 , in order to obtain data to calculate kinetic constants.

\section{1. (E)-2-[(Hydroxyimino) Methyl] Pyridine Synthesis}

In a round bottom flask of $50.0 \mathrm{~mL}$ were added $0.903 \mathrm{~g} \mathrm{(5.5}$ $\mathrm{mmol})$ of hydroxylamine sulfate in a solution of $47.6 \mu \mathrm{L}(0.5$ $\mathrm{mmol})$ of 2-pyridine carboxaldehyde (22) in $\mathrm{EtOH} / \mathrm{H}_{2} \mathrm{O}(20$ $\mathrm{mL}, 9: 1)$. Then, a solution of $\mathrm{NaOH}(0.55 \mathrm{mmol})$ in $\mathrm{H}_{2} \mathrm{O}(1$ $\mathrm{mL}$ ) was added slowly. The mixture was stirred and heated at $80{ }^{\circ} \mathrm{C}$ for 2 hours. The solvents were evaporated under reduced pressure and added with $20 \mathrm{ml}$ of distilled water to the residue. Then there were made three extractions with $20 \mathrm{~mL}$ of $\mathrm{CH}_{2} \mathrm{Cl}_{2}$. The organic phase was separated and dried with $\mathrm{Na}_{2} \mathrm{SO}_{4}$, and the solvent was evaporated at reduced pressure. The purification by chromatography on a silica gel columnproposed in literature was not performed, since the aim of this study was the study of the reaction kinetics, and not obtaining the pure product.



Figure 12. Synthesis of compound 23.

\subsection{Chromatographic Methods}

The steps of the synthesis were monitored by thin layer chromatography (TLC). TLC was performed using foil with silica gel $60 \mathrm{~F}_{254}(0.2 \mathrm{~mm}$ layer of aluminum), Merck trademark. For visualization of the chromatographic plates we used a developing chamber for TLC equipped with UV lamps at wavelengths of 254 and $365 \mathrm{~nm}$. The eluent used was a mixture of ethyl acetate and hexane at a ratio of $1: 1$.

\subsection{Characterization Methods}

The synthesized compounds were characterized by melting 
point, nuclear magnetic resonance spectroscopy of hydrogen and carbon $\left({ }^{13} \mathrm{C}\right.$ and ${ }^{1} \mathrm{H}$ NMR $)$ and mass spectrometry coupled with gas chromatography (GC-MS). The melting point and spectroscopic analysis of ${ }^{1} \mathrm{H}$ NMR and ${ }^{13} \mathrm{C}$ were performed at the Military Institute of Engineering (IME).

Melting points were determined using a Melt-Temp II device. The ${ }^{1} \mathrm{H}-\mathrm{NMR}$ spectra $(600 \mathrm{MHz})$ and ${ }^{13} \mathrm{C}(150 \mathrm{MHz})$ were obtained on a Varian spectrometer using $5 \mathrm{~mm}$ tubes, tetramethylsilane (TMS) as internal reference and deutered chloroform $\left(\mathrm{CDCl}_{3}\right)$ as solvent.

The spectrometric analyzes were performed at the Chemistry Institute of the Federal University of Rio de Janeiro (UFRJ) on a Shimadzu equipment. The analysis conditions were: HP-5 column $(30 \mathrm{~m} \times 0.25 \mathrm{~mm}$ DI, $0.25 \mu \mathrm{M}$ film, Agilent, Waldbronn, Germany); Ramp: after 1 minute at $50^{\circ} \mathrm{C}$ the temperature was raised at $25^{\circ} \mathrm{C} \mathrm{min}^{-1}$ to $300^{\circ} \mathrm{C}$ and maintained at $300^{\circ} \mathrm{C}$ for 4 minutes; injector temperature = $290^{\circ} \mathrm{C}$; split ratio 1:20; the ionization energy was $70 \mathrm{eV}$.

\subsection{Methods for the Parameters Kinetic Survey}

After purification and characterization, the retention times of compound 23 and 2-pyridine carboxaldehyde were determined separately on GC/MS. In addition to that, the necessary time to begin another analysis was identified.

When starting a new reaction, a $500 \mu \mathrm{L}$ aliquot of the new reaction solution was pulled out and added to $500 \mu \mathrm{L}$ of methanol. After filtration the aliquot was analyzed by GC/MS. These procedures were repeated at 25 min intervals.

The concentration-time graph was obtained by analysis of the GC/MS and the instantaneous derived calculated using equations (14), (15) and (16). With these data, the straight-line fit to equation (5), permitted the calculation of the desired kinetic parameters.

\section{Results and Discussion}

\section{1. (E)-2-[(Hydroxyimino)Methyl] Pyridine synthesis}

The synthesis of compound 23 was developed in one step. A TLC performed after 2 hours from the beginning of the reaction, indicated the absence of starting materials and the completion of the reaction (Figure 12). The retention factors $\left(\mathrm{R}_{\mathrm{f}}\right)$ of the starting material and the product were 0.65 and 0.5 respectively. After TLC analysis the reaction was interrupted and the acidity of the reaction solution pointed to $\mathrm{pH}=5$.

Figure 13 shows a proposed mechanism for the synthesis of compound 23 , occurring through a nucleophilic addition of hydroxylamine in carbonyls [27]. First neutralization occurs between hydroxylamine sulfate and sodium hydroxide, where the hydroxyl of such base abstracts a proton from the hydroxylamine ion, leaving a free pair of electrons on the nitrogen of hydroxylamine. After, the neutral hydroxylamine formed performs a nucleophilic attack on the carbonyl group of the starting material, leading to formation of intermediate 26 , which can be detected by NMR [28]. The reaction follows with protonation of intermediate 26 , due to the acidic $\mathrm{pH}$, causing a dewatering and forming the double bond between carbon and nitrogen, followed by the deprotonation of nitrogen.

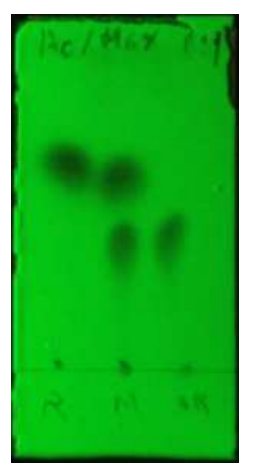

Figure 13. TCL of the reaction medium after 2 hours of reaction.

After purification, orange crystals were produced. This product had a melting point in the range $102,8-107,0^{\circ} \mathrm{C}$ close to that reported in the literature $\left(110-112^{\circ} \mathrm{C}\right)$ [29]. As the last step of purification was not done, compound 23 probably had trace impurities, so the melting point obtained was not exactly the same reported in literature.



<smiles>CCOC(O)C([Hg])NO</smiles><smiles>[H][R]([H])([H])C(=C)c1ccccn1</smiles><smiles>C=[I+]</smiles><smiles>C=COc1ccccc1</smiles><smiles>O/[NH+]=C/c1ccccn1</smiles>

<smiles>O/N=C/c1ccccn1</smiles>

(23)

Figure 14. Mechanism proposed to the synthesis of compound 23

\section{2. (E)-2-[(Hydroxyimino) Methyl] Pyridine Characterization}

Compound 23had the structure elucidated by NMR $\left({ }^{1} \mathrm{H}\right.$ and $\left.{ }^{13} \mathrm{C}\right)$. The chemical shifts for carbons and hydrogens obtained are shown in Table 2. In Table 3 it is possible to compare the our data with those reported in the literature [30]. 
Table 2. ${ }^{1} H$ NMR spectrum shifts of compound 23

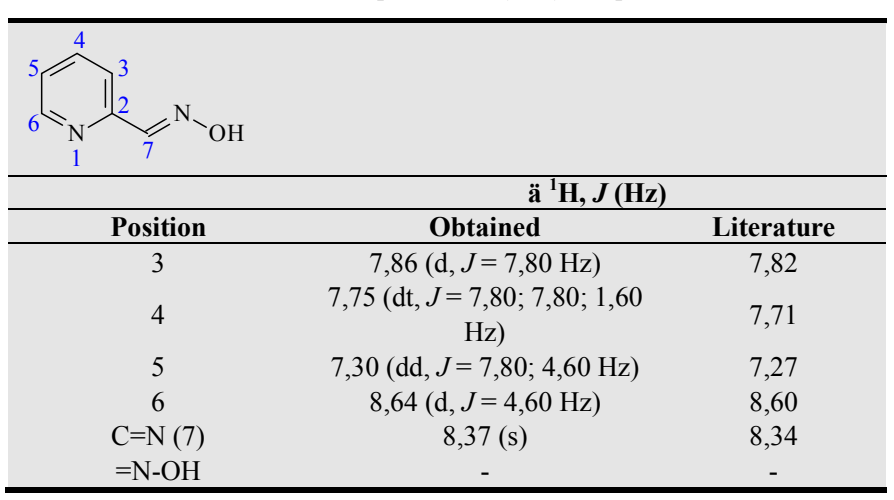

Table 3. ${ }^{13}$ C NMR spectrum shifts of compound 23 .

\begin{tabular}{ccc}
\hline \\
\multicolumn{2}{c}{} \\
\hline Position & $\ddot{\mathbf{a}}^{13} \mathbf{C}$ (ppm) \\
\hline 2 & Obtained & Literature \\
\hline 3 & 151,7 & 152,0 \\
4 & 121,1 & 121,5 \\
5 & 137,1 & 137,7 \\
6 & 124,1 & 124,4 \\
$\mathbf{C = N}(7)$ & 149,7 & 149,9 \\
\hline
\end{tabular}

In the ${ }^{13} \mathrm{C}$-NMR spectrum there was a signal at $\delta=149.9$ ppm relative to the $\mathrm{C}_{7}$ in the oxime group; besides the signals at $\delta=151.7,121.1,137.1,124.1$ and 149.7 , referring to $C_{2}$, $\mathrm{C}_{3}, \mathrm{C}_{4}, \mathrm{C}_{5}$ and $\mathrm{C}_{6}$ of the ring, respectively.

\subsection{Kinetic Parameters Survey}

The retention time obtained in the GC/MS analysis of compound 22 was $3.9 \mathrm{~min}$, as shown in the chromatogram in Figure 15. Compound 23 showed a retention time in the GC/MS of 5.9 min, as shown in Figure 16.



Figure 15. Chromatogram expansion of compound 22.

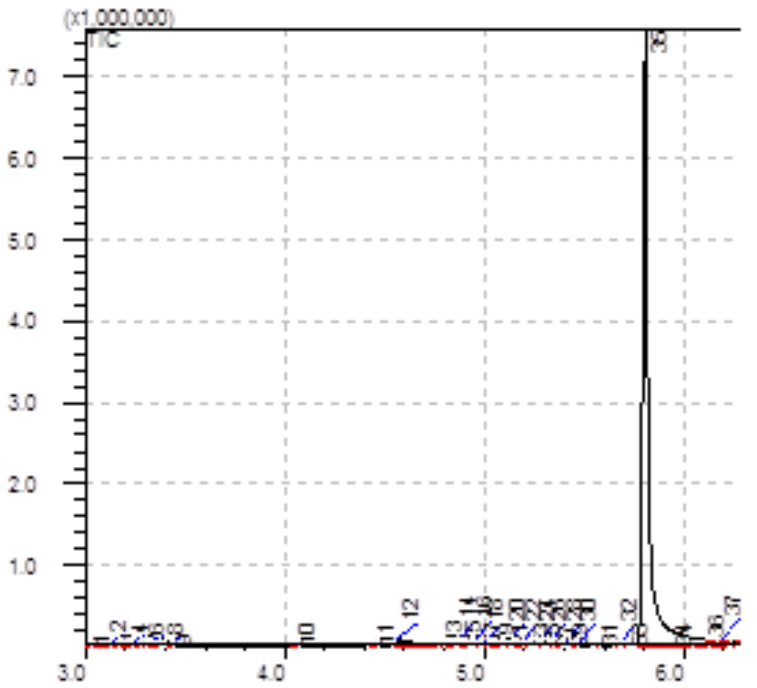

Figure 16. Chromatogram expansion of compound 23.

As compounds 22 and 23 presented distinct $R_{t}$, it was possible to identify, using the GC/MS, each of the compounds when they were together in solution.

In order to obtain a relationship between the concentration of the starting material and the time it was held a new reaction for removing aliquots at regular intervals and inserting in the GC/MS after properly preparation, at intervals of $25 \mathrm{~min}$.

The new reaction occurred according to the literature, namely at $80^{\circ} \mathrm{C}$. When doing the analysis of the first aliquot, at time $0 \mathrm{~min}$, the chromatogram indicated the absence of the reagent peak (Figure 17). This fact indicates that the conversion of starting material is quickly reached, and it is impossible lifting the relationship between the concentration of the starting material and time.

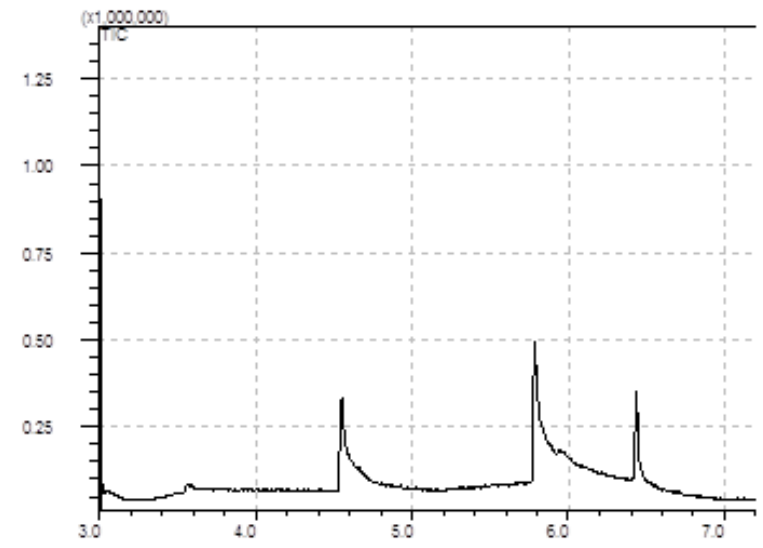

Figure 17. Chromatogram expansion of aliquot at $T=80^{\circ} \mathrm{C}$ and $t=0 \mathrm{~min}$.

In order to establish the relationship concentration versustime, a new reaction was performed. As the Arrhenius equation (3) establishes a relationship between " $\mathrm{k}$ " and temperature, the new reaction was carried out at a lower temperature $\left(20^{\circ} \mathrm{C}\right)$. At this temperature, a small peak, related to the starting material, was observed at the initial time. However, at the time of $25 \mathrm{~min}$, the chromatogram indicated 
the absence of the reagent peak.Thus, it would only be possible to determine the concentration of the starting material at the initial time, not being possible to perform the calculations required for determination of kinetic parameters.

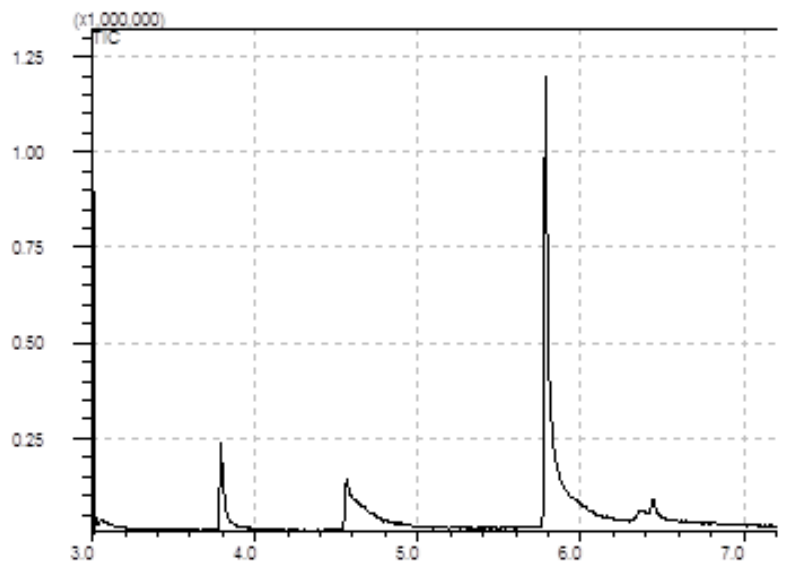

Figure 18. Chromatogram expansion of aliquot at $T=20^{\circ} \mathrm{C}$ and $t=0 \mathrm{~min}$.

This analysis also showed that the conversion of the starting material is quickly reached and the reaction is completed in less than 25 min.

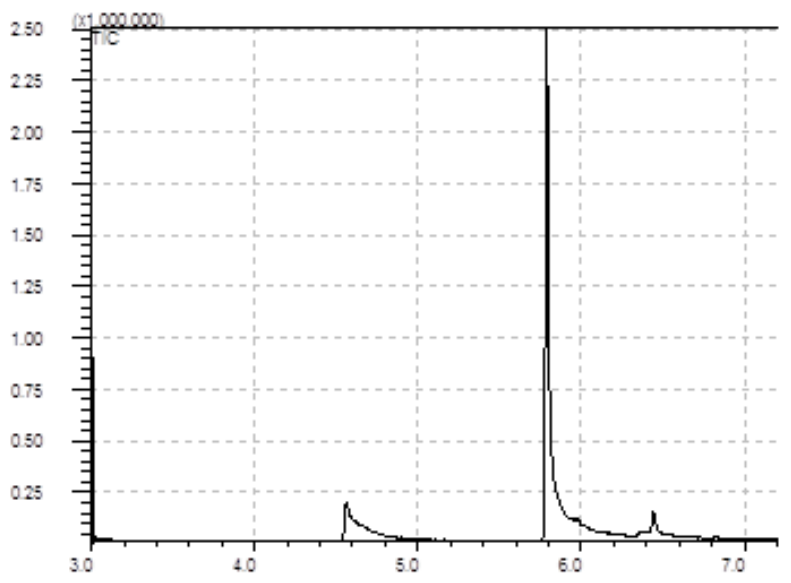

Figure 19. Chromatogram expansion of aliquot at $T=20^{\circ} \mathrm{C}$ and $t=25 \mathrm{~min}$

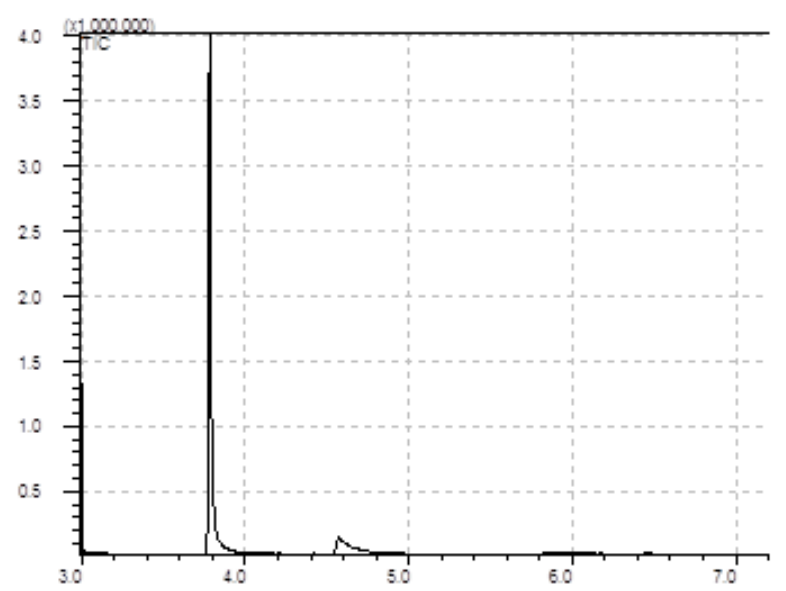

Figure 20. Chromatogram expansion of aliquot at $T=0^{\circ} \mathrm{C}$ and $t=0 \mathrm{~min}$.

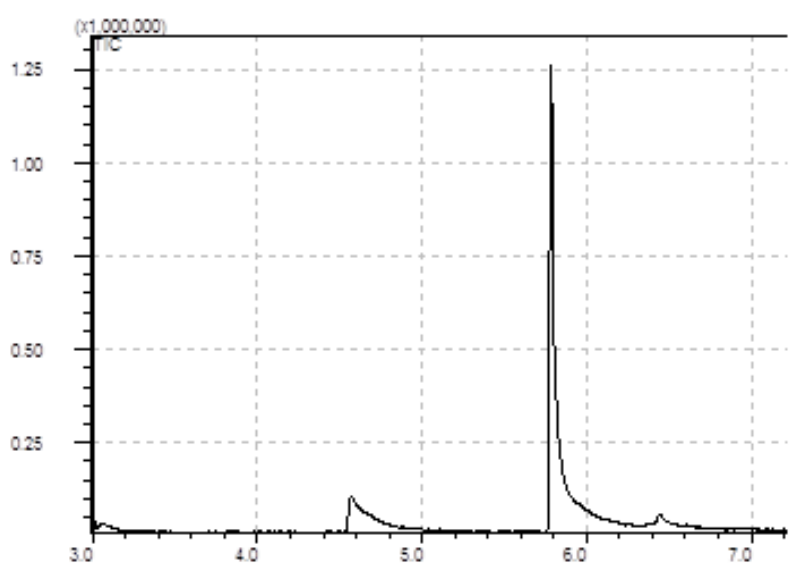

Figure 21. Chromatogram expansion of aliquot at $T=0^{\circ} \mathrm{C}$ and $t=25 \mathrm{~min}$.

Also with the aim of obtaining a relative concentration against time the reaction was again repeated, but at $0{ }^{\circ} \mathrm{C}$. At this temperature, it was clearly observed at the initial instant, a peak related to the starting material (Figure 19) contrary to what was observed in the experiment at $20^{\circ} \mathrm{C}$ (Figure 18). However, at the time of $25 \mathrm{~min}$, the chromatogram also indicated the absence of the peak of the reagent (Figure 20).

Once again it was not possible to establish the relationship concentration versus time, making it impossible to calculate the kinetic parameters, in addition to observing a rapid conversion of the starting material.

All these results regarding the reaction kinetics of the synthesis of compound 23 prevented the collection of information to start the calculation of the reactor. However, the kinetic does not provide all the information necessary for that purpose.

The model used in this study for calculation of the kinetic parameters assumes that the reactor is homogeneous, which is a hypothesis applied very well in laboratory scale. However, there is a difficulty in maintaining homogeneous reaction medium and a constant temperature when it comes to a larger scale. Therefore, for reactor calculation, the macroscopic system must be considered, where factors such as fluid mechanics, the degree of agitation, heat and mass transfer can influence the temperature gradients and concentration of the reaction medium.

\section{Conclusion}

All results obtained in GC/MS showed that the conversion of the starting material is very fast. It was not possible to monitor the variation of reagent concentration over time through GC/MS.

During the phase of obtaining kinetic parameters of this work we tried to study the factors that influence the kinetics of the reaction, in order to establish a relationship between concentration and time. One of these factors is the temperature. Therefore, experiments were performed at three different temperatures $\left(0^{\circ} \mathrm{C}, 20^{\circ} \mathrm{C}\right.$ and $\left.80^{\circ} \mathrm{C}\right)$, with similar results. This indicates that, for the purposes of this project, the temperature does not have significant influence on the 
kinetics of the synthesis of compound 23. Even at room temperature, it is possible to achieve high conversion rates of the starting material in short intervals.

In conclusion our results show that the reaction kinetics is not the primary factor influencing the conversion of the starting material and other parameters should be further studied, such as thermodynamics, fluid mechanics, heat transfer and mass transfer.

\section{Acknowledgments}

The authors wish to thank the Brazilian financial agencies Conselho Nacional de Desenvolvimento Científico e Tecnológico (CNPq) (Grant 304557/2012-9), Fundação de Amparo ao Ensino e Pesquisa do Estado do Rio de Janeiro (FAPERJ) (Grant E-26/102.993/2012) and Coordenação de Aperfeiçoamento de Pessoal de Nível Superior/Ministério da Defesa (CAPES/MD) (Edital PRODEFESA 2008, grant no PD 1782/2008) for financial support, and the Military Institute of Engineering (IME) and Federal University of Rio de Janeiro (UFRJ) for providing the physical infrastructure and working space.

This work was also supported by Excellence project FIM.

In particular, STM acknowledges the support from CAPES (Brazil), and FAPERJ (Brazil).

\section{References}

[1] R. T. Delfino, T. S. Ribeiro and J. D. Figueroa-Villar, "Organophosphorus compounds as chemical warfare agents: a review," Journal of the Brazil Chemical Society, vol. 20, pp. 407-428, 2009.

[2] Brasil. Ministério do Exército, C3-40: Defesa contra ataques químicos, biológicos e nucleares, $1^{a}$ edição ed., Brasília: EGGCF, 1987.

[3] J. O. S. Giacoppo, W. E. A. Lima, K. Kamil, T. C. C. França, E. F. F. da Cunha and T. C. Ramalho, "Guerra Química: Perspectivas no Estudo de Reativadores da Enzima Acetilcolinesterase Inibida por Organofosforados," Revista Virtual de Química, n. 6, pp. 653-670, 2013.

[4] Goodman-Gilman, As Bases Farmacológicas da Terapêutica, $11^{\mathrm{a}}$ ed., Rio de Janeiro: McGraw-Hill Interamericana do Brasil, 2006.

[5] P. H. Raven and G. B. Johnson, Biology, 9th ed., McGraw-Hill, 2011.

[6] G. L. Patrick, A Introdution to Medicinal Chemistry, $2^{\mathrm{a}}$ edição ed., Ed. Oxford, 2001.

[7] E. d. C. Petronilho, A. C. Pinto and J. D. F. Villar, "Acetilcolinesterase: alzheimer e guerra química," Revista Militar de Ciência e Tecnologia, vol. XXVIII, pp. 3-14, 2011.

[8] D. d. R. Voris and L. Mayer, "Estudo de óleos essenciais terpenóides e fenilpropanóides como inibidores da acetilcolinesterase," Rio de Janeiro, 2012.

[9] J. B. Domingos, E. Longhinotti, V. G. Machado and F. Nome, "A Química dos Ésteres de Fósforo," Química Nova, vol. 26, pp. $475-753,2003$.
[10] R. S. Alvim, V. S. Vaiss, A. A. Leitão and I. B. Jr., "A Química Teórica a Serviço da Defesa Química: Degradação de Agentes Neurotóxicos em Superfícies de Óxido e Hidróxido de Magnésio," Revista Virtual de Química, vol. 6, n. 3, pp. 687-723, 2014.

[11] E. C. Petronilho, "Síntese e avaliação de hidrazonas como inibidoras e reativadoras da acetilcolinesterase," Rio de Janeiro, 2011.

[12] K. J. D. M. K. Kuka, "Structural Requeriments of Acetylcholinesterase Reactivators," Mini-Reviews in Medicinal Chemistry, no. 6, pp. 269-277, 2006.

[13] J. D. Hoekman, M. Hite, A. Brunelle, J. Relethford e R. J. Ho, "Nasal Drug Delivery Device". Patente US20140014104 A1, 3 Janeiro 2014.

[14] T. T. Marrs, R. L. Maynard and F. Sidell, Chemical Warfare Agents: Toxicology and Treatment, $2^{\text {a }}$ Edição ed., John Wiley \& Sons Ltda., 2007.

[15] X.-P. Zhang, J. Liu, J.-X. Zhang, J.-H. Huang, C.-Z. Wan, C.-H. $\mathrm{Li}$ and X.-Z. You, "Synthesis and ferroeletric properties of platinum(II) complexes with chiral isoxazoline ligand," Polyhedron, vol. 60, pp. 85-92, 2013.

[16] K. Musilek, J. Kucera, D. Jun, V. Dohnal, V. Opletalova and K. Kuca, "Monoquaternary pyridinium salts with modified side chain - synthesis and evaluation on model of tabun- and paraoxon-inhibited acetylcholinesterase," Bioorganic \& Medicinal Chemistry, vol. 16, n. 17, p. 8218-8223, 2008.

[17] J. Kaminski, K. Knutson and N. Bodor, "A convenient method of anion exchange in quaternary salts," Tetrahedron, vol. 34, n. 19, pp. 2857-2859, 1978.

[18] O. Levenspiel, Chemical Reaction Enginnering, $3^{\text {a }}$ edição ed., John Wiley \& Sons, 1998.

[19] L. D. Schmidt, The Enginnering of Chemical Reactions, New York: Oxford University Press, 1998.

[20] R. W. Missen, C. A. Mims and B. A. Saville, Introduction to Chemical Reaction Engineering and Kinetics, John Wiley \& Sons, 1999.

[21] H. S. Fogler, Elements of Chemical Engineering, $4^{\mathrm{a}}$ ed., Pearso Education, 2006.

[22] G. W. Castellan, Physical Chemistry, $3^{\text {a }}$ Edição ed., Addison-Wesley Publishing Company, Inc. , 1983.

[23] P. Atkins and J. d. Paula, Physical Chemistry, 9a Edição ed., New York: W. H. Freeman and Company, 2010.

[24] H. Tominaga and M. Tamaki, Chemical Reactions and Reactor Design, New York: John Wiley \& Sons, 1997.

[25] A. O. Fortuna, Técnicas Computacionais para Dinâmica dos Fluidos: Conceitos Básicos e Aplicações, São Paulo: Editora da Universidade de São Paulo, 2000.

[26] R. L. Burden and J. D. Faires, Análise Numérica, São Paulo: Thompson Learning, 2003.

[27] J. McMurry, Organic Chemistry, $7^{\text {a }}$ Edição ed., Brooks/Cole Thomson Learning, Inc., 2008.

[28] J. March and M. B. Smith, March's Advanced Organic

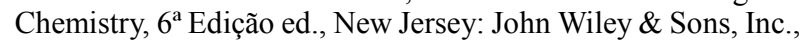
2007. 
[29] Sigma-Aldrich, "Material Safety Data Sheet," 2012. [Online]. Available:

http://www.sigmaaldrich.com/MSDS/MSDS/DisplayMSDSPa ge.do? country $=$ BR\&language $=$ pt\&productNumber $=131628 \&$ brand $=$ ALDRICH\&PageToGoToURL $=$ http $\% 3 \mathrm{~A} \% 2 \mathrm{~F} \% 2 \mathrm{Fww}$ w.sigmaaldrich.com $\% 2 \mathrm{~F}$ catalog $\% 2 \mathrm{Fsearch} \% 3 \mathrm{Finterface} \% 3 \mathrm{D}$ All\%26term\%3Daldoxime \%2520pyridine $\% 26 \mathrm{~N} \% 3 \mathrm{D} 0 \% 26$ foc us\%3Dproduc. [Acesso em 01042014 ].
[30] R. Janicki, "Synthesis, crystal structure and spectral properties of diammonium dihydrogen $\mathrm{N}$-(methylene-2-pyridine)-N,N,-di-(methylenephosphonate)," Journal of Molecular Structure, n. 1036, pp. 35-41, 2013. 